TI 2017-011/VI

Tinbergen Institute Discussion Paper
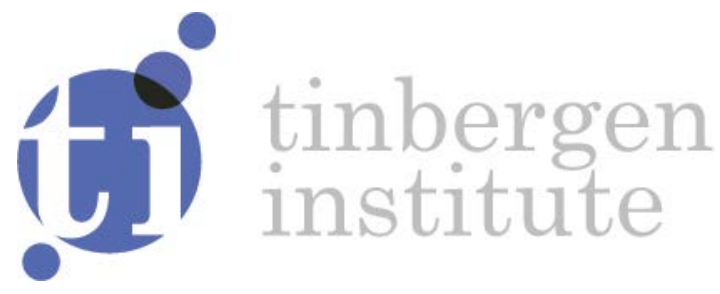

\title{
Why is the Long-Run Tax on Capital Income Zero? Explaining the Chamley-Judd Result
}

Bas Jacobs ${ }^{1}$

Alexandra Victoria Rusu ${ }^{2}$

${ }^{1}$ Erasmus University Rotterdam, Tinbergen Institute and CESifo.

${ }^{2}$ Erasmus School of Economics, Erasmus University Rotterdam and Tinbergen Institute. 
Tinbergen Institute is the graduate school and research institute in economics of Erasmus University Rotterdam, the University of Amsterdam and VU University Amsterdam.

Contact: discussionpapers@tinbergen.nl

More Tl discussion papers can be downloaded at http://www.tinbergen.nl

Tinbergen Institute has two locations:

Tinbergen Institute Amsterdam

Gustav Mahlerplein 117

1082 MS Amsterdam

The Netherlands

Tel.: +31(0)205984580

Tinbergen Institute Rotterdam

Burg. Oudlaan 50

3062 PA Rotterdam

The Netherlands

Tel.: +31(0)10408 8900 


\title{
Why is the Long-Run Tax on Capital Income Zero? Explaining the Chamley-Judd Result*
}

\author{
Bas Jacobs** and Alexandra Rusu***
}

January 12, 2017

\begin{abstract}
Why is it optimal not to tax capital income in the long-run in Chamley (1986) and Judd (1985)? This paper demonstrates that the answer follows standard intuitions from the commodity tax literature. In the steady state, Engel curves for consumption are linear in labour earnings, irrespective of the utility function adopted. Thus, in the steady state, consumption demands in each period become equally complementary to leisure over time. This renders taxes on capital income redundant, since they cannot alleviate distortions from taxing labour income. The argument that taxes on capital income should be zero because distortions explode in finite time is relevant only if restrictions are imposed on the utility function. We show how these restrictions imply that consumption demands in each period are equally complementary to leisure over time. We also demonstrate that the optimal tax on capital income is zero irrespective of whether the gross interest rate is endogenous. This contradicts arguments that the entire burden of capital income taxes is shifted to labour through general-equilibrium effects on the interest rate.
\end{abstract}

JEL-code: H2

Key words: taxation of capital income, zero capital income tax, Corlett-Hague motive, Chamley-Judd result

\section{Introduction}

Should capital income be taxed or not? This is one of the oldest and most important questions in public finance. However, the literature has not yet settled on a definite answer and the issue remains controversial from a policy perspective ${ }^{1}$. The arguments against taxing capital income rely on Chamley (1986) and Judd (1985), who suggest that in the long run the required revenue should be generated solely through taxing labour income. Thus, it is never optimal to tax capital income in the long run, but it might be optimal to tax it in the short run. Although

\footnotetext{
${ }^{*}$ The authors would like to thank Robin Boadway, Emmanuel Saez and seminar participants at the Tinbergen Institute Rotterdam for useful comments and suggestions. All remaining errors are our own.

** Erasmus University Rotterdam, Tinbergen Institute and CESifo. Address: Erasmus School of Economics, Erasmus University Rotterdam, PO Box 1738, 3000 DR Rotterdam, The Netherlands. Phone: +31 10 4081452/1441. Fax: +31 10 4089166. E-mail: bjacobs@ese.eur.nl. Homepage: http://people.few.eur.nl/ bjacobs.

${ }^{* * *}$ Erasmus School of Economics, Erasmus University Rotterdam and Tinbergen Institute. Address: Erasmus School of Economics, Erasmus University Rotterdam, PO Box 1738, 3000 DR Rotterdam, The Netherlands. E-mail: rusu@ese.eur.nl. Homepage: http://www.alexrusu.com.

${ }^{1}$ For example, the main editors of the Mirrlees Review conclude that taxing the the (normal) return to savings is undesirable (Mirrlees et al., 2011). However, Banks and Diamond (2010), who also write a chapter in the Mirrlees Review, argue that taxing the returns to capital is optimal. Mankiw, Weinzierl, and Yagan (2009) argue against taxing capital income in the Journal of Economic Literature, whereas Diamond and Saez (2011) argue in favor of taxing capital income in that very same journal.
} 
there is a large literature on the robustness of the zero-capital income tax result ${ }^{2}$, the economic mechanism and the intuition behind Chamley (1986) and Judd (1985) remain elusive.

In this paper, we argue that the zero capital income tax result can be explained with standard principles from the theory of optimal linear commodity taxation. The tax on capital income should be seen as a differentiated tax on consumption at different dates, so that in the optimum, it should be zero if optimal consumption taxes are uniform. The main intuition for optimal uniform commodity taxation in the Ramsey (1927) framework is found in Corlett and Hague (1953): if goods that are stronger complements to leisure are taxed at higher rates, individuals substitute away from leisure and work more. Since labour supply is distorted downwards, commodity tax differentiation can alleviate distortions of the labour income tax, but at the expense of distorting commodity demands. Formally, optimal commodity taxes are uniform only if consumption Engel curves are linear and pass through the origin ${ }^{3}$. Therefore, uniform commodity taxation is optimal if the utility function is weakly separable between consumption and leisure and homothetic in consumption ${ }^{4,5}$. In that case, different commodities are equally complementary to leisure and commodity tax differentiation only causes goods market distortions, without alleviating labour market distortions.

We analyze a version of the Chamley-Judd model due to Ljungqvist and Sargent (2004). An infinitely-lived representative agent decides how much to work and save in each period. The government needs to finance an exogenous stream of outlays and optimises linear taxes on labour and capital income such that the lifetime utility of the representative individual is maximised. To avoid a degenerate steady state or a first-best solution, we assume that initial capital endowments are null and first-period production only uses labour ${ }^{6}$. In the steady state, optimal taxes on capital income are shown to be zero. Our explanation for this result is that the steady-state assumption in Chamley (1986) and Judd (1985) forces all consumption Engel curves to be time-invariant and linear, with no need for further restrictions on the utility function. As a result, in the steady state, consumption in each period becomes equally complementary to leisure at all times. Proportional taxes on capital income impose the same distortions on labour supply as proportional taxes on labour income, but in addition also distort saving. Therefore, the government should not distort intertemporal consumption decisions in order to alleviate labour supply distortions and optimal taxes on capital income should become zero ${ }^{7}$. We thus

\footnotetext{
${ }^{2}$ See e.g. Jones, Manuelli, and Rossi (1997), Krusell, Kuruşçu, and Smith (2010) and Straub and Werning (2014).

${ }^{3}$ The Corrlett-Hague motive for differentiated commodity carries over to Mirrleesian frameworks with optimal non-linear taxation of labour income, cf. Atkinson and Stiglitz (1976) and Jacobs and Boadway (2014). The Atkinson and Stiglitz (1976) theorem shows that uniform commodity taxation is optimal if the government can levy a non-linear tax on labour income and preferences are weakly separable between consumption over time and leisure. Hence, linear Engel curves are no longer required to obtain optimally uniform commodity taxation if income taxes are non-linear. See also Ordover and Phelps (1979) for an application of optimal taxes on capital income in a 2-period OLG framework with optimal non-linear taxes on labour income.

${ }^{4}$ Deaton (1979) demonstrates that uniform commodity taxation is even obtained in settings with heterogeneous agents if preferences are of the Gorman (1961) polar form. However, uniform commodity taxation can then only be obtained if the government has access to a (non-individualized) lump-sum tax. This instrument is ruled out in the Chamley-Judd setting with a representative agent to obtain a non-trivial second-best analysis.

${ }^{5}$ Erosa and Gervais (2002) use an OLG version of the Ramsey models in Chamley (1986) and Judd (1985) to demonstrate that the optimal tax on capital income is generally non-zero.

${ }^{6}$ Straub and Werning (2014) showed that the size of initial government debt can determine the existence and nature of the steady-state, which are issues that we want to avoid.

${ }^{7}$ Our paper is meant as a positive, methodological contribution aimed at clarifying the result of Chamley
} 
establish a close link between the zero-tax result in Chamley (1986) and Judd (1985) and the theory of optimal commodity taxation.

By showing that standard optimal taxation principles underlie the zero tax on capital income, we reveal that the explanations previously offered by the literature can be misleading. The first intuition, provided by Judd (1999) and subsequently used in Banks and Diamond (2010), argues that the economy need not converge to a steady state for the optimal long-run tax on capital income to be zero. Since capital income taxes impose an exponentially-growing tax burden on consumption in the more distant future, it can never be optimal to set them to strictly positive rates in the long run. Such an explosive path of tax distortions in finite time is incompatible with standard Ramsey principles, which insist that tax distortions be smoothed out over time. Therefore, in order to rule out exponentially growing tax burdens, taxes on capital income should become zero in finite time.

We agree with Judd (1999) that the intuition for Chamley-Judd result should be firmly rooted in optimal taxation principles. However, the Ramsey logic is applicable only when consumption demands depend solely on own prices. Hence, strong restrictions need to be made on the utility function: additive separability over time and separability between consumption and leisure. Only under these restrictions is the Ramsey tax smoothing intuition equivalent to the more general Corlett-Hague logic; the commodities that are less price elastic are also the commodities that more complementary to leisure. See also Atkinson and Stiglitz (1980, Ch. $12)$.

Judd (1999) argued that convergence to a steady-state is not required in order to get zero optimal capital income taxes. In finite time, capital income taxes are zero either if the multipliers on the government budget constraints are bounded or if preferences are such that the multipliers are constant. Straub and Werning (2014) correctly criticise imposing constraints on endogenous multipliers, since doing so boils down to assuming that the optimal optimal tax on capital income is zero. We add to the analysis in Straub and Werning (2014) by showing that the multipliers on the government budget constraints are constant only if preferences are such that consumption is equally complementary to leisure at all times and the optimal capital income tax is in fact zero in every period.

The second argument why capital income taxes are optimally zero can be found in Auerbach and Kotlikoff (1983), Correia (1996), Mankiw, Weinzierl, and Yagan (2009) and Piketty and Zucman (2014). It is argued that, in the steady state, all taxes on capital income are shifted to labour due to general-equilibrium effects on factor prices. Therefore, it is better to tax labour income directly and avoid distortions in the capital market. This argument relies on the notion that in the steady state, the net return to capital is completely determined by exogenous factors such as the depreciation rate and the rate of time preference. Consequently, any tax on capital income has to result in a one-to-one increase of the gross return to capital to keep the net return to capital constant. This requires a fall in the steady-state capital stock, which decreases wages. As a result, the tax burden is completely shifted to labour. We analyse an

(1986) and Judd (1985) that capital income should not be taxed in the long run. It is not meant to serve as a normative policy prescription. Banks and Diamond (2010), Diamond and Saez (2011) and Jacobs (2013) have argued that capital income should be taxed at positive rates for various reasons that the framework of Chamley (1986) and Judd (1985) cannot address. 
open-economy version of the Chamley-Judd model, where we switch off any general-equilibrium effects on factor prices that occur due to the taxation of capital income. This allows us to confirm the results of Diamond and Mirrlees (1971) in a dynamic setting: the expressions for optimal taxes in partial equilibrium are identical to those obtained in general equilibrium. Therefore, general-equilibrium effects in factor prices shifting the entire tax burden towards labour cannot be an explanation why capital income should not be taxed in the long-run. This contrasts with the impressions that are given in Auerbach and Kotlikoff (1983), Correia (1996), Mankiw, Weinzierl, and Yagan (2009), and Piketty and Zucman (2014).

The present work complements the analysis of Straub and Werning (2014), who showed that the results in Chamley (1986) and Judd (1985) are not as general as previously thought. By using a model with additively separable time preferences, we focus on the only case identified by Straub and Werning (2014) where the capital stock is positive and taxes on capital income are zero in the steady state. Straub and Werning (2014) show that if preferences are not additively separable over time, the zero capital income tax in Chamley (1986) is imposed on a zero tax base, or it coexists with a zero labour income tax. To show the general nature of our argument, we analyse a model where preferences are not time-separable and identify the case in which consumption and leisure are equally complementary at all times. If preferences are not time-separable, but weakly separable between consumption and leisure and homothetic with respect to both, consumption at different times is equally complementary to leisure at all times. Consequently, the tax on capital income is always zero.

The rest of the paper is structured as follows. In the next section, we introduce the generalequilibrium model and show that the Corrlett-Hague motive for commodity tax differentiation vanishes in the steady state of the Chamley-Judd model. The reason is that consumption Engel curves become linear in income in the steady-state. In the third section, we show how our interpretation relates to the other intuitions in the literature. A final section concludes. An Appendix contains the proofs of some Lemma's.

\section{Long-run capital income taxes in general equilibrium}

\subsection{Representative individual}

This section starts with a general-equilibrium formulation of a closed economy as in Chamley (1986) and Judd (1999), where utility is time-separable and time is indexed by $t$. We follow the representation given in Ljungqvist and Sargent (2004). There is an infinitely-lived representative individual who maximises the discounted value of lifetime utility:

$$
\sum_{t=0}^{\infty} \beta^{t} u\left(c_{t}, l_{t}\right), \quad u_{c},-u_{l}>0, \quad u_{c c}, u_{l l}<0 .
$$

The utility function $u\left(c_{t}, l_{t}\right)$ in each period is increasing, strictly concave and twice differentiable in both consumption $c_{t}$ and leisure $1-l_{t}$. The individual's pure rate of time preference is captured by the discount factor $\beta$ and her assets are denoted by $a_{t}$.

The representative individual owns no assets in period $0\left(a_{0}=0\right)$. Consequently, there is no motive to tax pure rents from (initial) asset endowments. By assuming zero initial assets, 
we avoid the possibilities of a degenerate steady state or a first-best solution, see also Straub and Werning (2014). The individual is endowed with one unit of time per period, which must be divided between work and leisure. In each period, labour has to satisfy a time constraint: $0 \leq l_{t} \leq 1$. The gross interest rate is $r_{t}$ and the gross wage rate is $w_{t}$. The government levies a proportional tax on capital income $\tau_{t}^{K}$ and a proportional tax on labour income $\tau_{t}^{L}$ in every period. Consequently, the individual's budget constraint is:

$$
\begin{aligned}
& a_{t+1}=\left(1+\left(1-\tau_{t}^{K}\right) r_{t}\right) a_{t}+\left(1-\tau_{t}^{L}\right) w_{t} l_{t}-c_{t}, \quad t \geq 0, \quad a_{0}=0, \\
& \lim _{t \rightarrow \infty} \frac{a_{t+1}}{\prod_{s=1}^{t}\left(1+\left(1-\tau_{s}^{K}\right) r_{s}\right)}=0 .
\end{aligned}
$$

Equation (3) says that the present discounted value of the individual's terminal assets should be 0 , thus ruling out explosive asset paths (a no Ponzi-scheme condition). By iterating the individual's budget constraint forward and applying the transversality condition in equation (3), we obtain her lifetime budget constraint:

$$
\sum_{t=0}^{\infty} \frac{c_{t}}{\prod_{s=1}^{t}\left(1+\left(1-\tau_{s}^{K}\right) r_{s}\right)}=\sum_{t=0}^{\infty} \frac{\left(1-\tau_{t}^{L}\right) w_{t} l_{t}}{\prod_{s=1}^{t}\left(1+\left(1-\tau_{s}^{K}\right) r_{s}\right)}
$$

The representative individual's problem consists of choosing her sequences of consumption $\left\{c_{t}\right\}_{t=0}^{\infty}$, labour supply $\left\{l_{t}\right\}_{t=0}^{\infty}$ and assets $\left\{a_{t+1}\right\}_{t=0}^{\infty}$ such that the lifetime utility (1) is maximised subject to the budget constraint (4). Assuming an interior solution for $l_{t}$ and denoting the multiplier on the period $t$ budget constraint by $\beta^{t} \lambda_{t}$, we can obtain the first-order conditions that govern optimal labour supply and saving behaviour:

$$
\begin{aligned}
u_{c_{t}} & =\lambda_{t}, \quad t \geq 0, \\
-u_{l_{t}} & =\lambda_{t}\left(1-\tau_{t}^{L}\right) w_{t}, \quad t \geq 0, \\
\frac{\lambda_{t}}{\beta \lambda_{t+1}} & =1+\left(1-\tau_{t+1}^{K}\right) r_{t+1}, \quad t>0 .
\end{aligned}
$$

Equation (5) states that in the optimum, the marginal benefit of consuming one extra unit, $u_{c_{t}}$, should be equal to the marginal cost $\lambda_{t}$ of doing so. Similarly, equation (6) shows that the individual should work until the marginal cost of sacrificing one extra unit of leisure, $-u_{l_{t}}$, is equal to the gain in utility due to having more income, $\lambda_{t}\left(1-\tau_{t}^{L}\right) w_{t}$. The Euler equation (7) describes the optimal allocation of consumption across time: the individual should save until her increase in utility from consuming marginally more in the current period $\left(\lambda_{t}\right)$ is the same as her discounted increase in utility from investing that consumption increment at market prices and consuming it the next period, $\beta\left(1+\left(1-\tau_{t+1}^{K}\right) r_{t+1}\right) \lambda_{t+1}$.

\subsection{Government}

The government's objective is to maximise the representative individual's utility, while satisfying an exogenous revenue requirement $g_{t}$ in every period. Like Chamley (1986) and Judd (1985), 
we assume that the government can credibly commit to the policies it sets ${ }^{8}$. Furthermore, we assume that the government can verify aggregate capital and labour income, but has no access to lump-sum taxes. Thus, it can use proportional taxes $\tau_{t}^{L}$ on labour income and $\tau_{t}^{K}$ on capital income and issuance of debt $d_{t+1}$ to raise revenue.

We assume that in period 0 , the initial level of debt is null: $d_{0}=0$. Since this is a deterministic model without default, government bonds and private assets are perfect substitutes. Perfect arbitrage thus ensures that the interest rate on government bonds equals the interest rate $r_{t}$ on other assets. Hence, the period-by-period government budget constraint reads as:

$$
\begin{aligned}
& d_{t+1}=\left(1+r_{t}\right) d_{t}+g_{t}-\tau_{t}^{L} w_{t} l_{t}-\tau_{t}^{K} r_{t} a_{t}, \quad t \geq 0, \quad d_{0}=0, \\
& \lim _{t \rightarrow \infty} \frac{d_{t+1}}{\prod_{s=1}^{t}\left(1+r_{s}\right)}=0 .
\end{aligned}
$$

The government debt $d_{t+1}$ also has to satisfy transversality condition (9) to rule out explosive paths for public debt.

\section{$2.3 \quad$ Firms}

There is a single representative firm that uses capital $k_{t}$ and labour $l_{t}$ to produce output. In all periods $t>0$, the production function is given by $f\left(k_{t}, l_{t}\right)$, which exhibits constant returns to scale, satisfies the Inada conditions ${ }^{9}$ and features positive and decreasing marginal returns to both capital and labour: $f_{l}, f_{k}>0, f_{l l}, f_{k k}<0$. Capital depreciates at rate $\delta$. In period 0 , the production function uses only labour: $f_{0}=A l_{0}$. This ensures that endowments are not required for starting the production process.Profit maximisation implies that marginal products equal marginal costs in each period:

$$
\begin{aligned}
f_{k}\left(k_{t}, l_{t}\right) & =r_{t}+\delta, \quad t>0, \\
f_{l}\left(k_{t}, l_{t}\right) & =w_{t}, \quad t>0, \\
A_{0} & =w_{0} .
\end{aligned}
$$

There are no pure profits in each period due to constant returns to scale in production.

\subsection{General equilibrium}

Equilibrium in the goods market requires that the total demand for goods - private consumption $c_{t}$, public consumption $g_{t}$, investment $k_{t+1}-(1-\delta) k_{t}$ - equal the supply of goods:

$$
c_{t}+g_{t}+k_{t+1}-(1-\delta) k_{t}=f\left(k_{t}, l_{t}\right), \quad t \geq 0 .
$$

\footnotetext{
${ }^{8}$ There is a well-known time-consistency problem in the optimal setting of capital taxes. Once capital is accumulated, capital owners cannot respond by withdrawing their investment. Hence, the government has an incentive to expropriate individuals by levying a tax on capital (Kydland and Prescott, 1977; Fischer, 1980).

${ }^{9}$ The Inada conditions are: $\lim _{k_{t} \rightarrow 0} f_{k}\left(k_{t}, l_{t}\right)=\lim _{l_{t} \rightarrow 0} f_{l}\left(k_{t}, l_{t}\right)=\infty$ and $\lim _{k_{t} \rightarrow \infty} f_{k}\left(k_{t}, l_{t}\right)=$ $\lim _{l_{t} \rightarrow \infty} f_{l}\left(k_{t}, l_{t}\right)=0$.
} 
Equilibrium in the capital market requires that the demand for capital by firms $k_{t}$ and demand of government debt $d_{t}$ equal the supply of assets by the representative individual $a_{t}{ }^{10}$ :

$$
k_{t}+d_{t}=a_{t}
$$

\subsection{Primal approach in general equilibrium}

The government's problem is to choose the sequence of taxes $\left\{\tau_{t+1}^{K}, \tau_{t}^{L}\right\}_{t=0}^{\infty}$ that maximises the representative individual's lifetime utility. In order to derive the optimal tax rules, we employ the primal approach to the optimal tax problem. First, the government optimally derives the second-best allocation $\left\{c_{t}, l_{t}, k_{t+1}\right\}_{t=0}^{\infty}$ subject to the resource and implementability constraints. Second, this allocation is decentralised using the tax instruments to obtain the same allocation as the outcome of a competitive equilibrium. An allocation is implementable if it satisfies Definition 1.

Definition 1. An allocation $\left\{c_{t}, l_{t}, k_{t+1}\right\}_{t=0}^{\infty}$ is implementable with proportional taxes on capital and labour income if it satisfies the following conditions:

- There exists a sequence of taxes $\left\{\tau_{t+1}^{K}, \tau_{t}^{L}\right\}_{t=0}^{\infty}$, factor prices $\left\{w_{t}, r_{t+1}\right\}_{t=0}^{\infty}$ and asset holdings $\left\{a_{t+1}\right\}_{t=0}^{\infty}$ such that the allocation solves the individual's problem, given the prices;

- There exist factor prices $\left\{w_{t}, r_{t+1}\right\}_{t=0}^{\infty}$, such that the firm maximises its profits every period;

- The allocation satisfies the government budget constraint (8) every period;

- The allocation satisfies the aggregate resource constraint (13) every period;

- The allocation satisfies the domestic capital market equilibrium condition (14) every period.

The next step is to derive the implementability constraint. First, use the individual's first order conditions (6) and (7) to substitute out the net prices in the individual's budget constraint (2). Multiply the result by $\beta^{t} u_{c_{t}}$, sum over the individual's lifetime and use the transversality condition for private assets (3) to find:

$$
\sum_{t=0}^{\infty} \beta^{t}\left(c_{t} u_{c_{t}}+l_{t} u_{l_{t}}\right)=0 .
$$

Lemma 1 shows that an allocation that satisfies the implementability (15) and aggregate resource constraints (13) is implementable with proportional taxes on capital and labour income. Therefore, instead of directly choosing the optimal taxes (the dual problem), we can solve the government's problem by choosing the implementable allocation that maximises the representative individual's utility (the primal problem). We can then use the optimal allocation to retrieve the optimal tax rules.

\footnotetext{
${ }^{10}$ Furthermore, the transversality condition for capital must hold: $\lim _{t \rightarrow \infty} \frac{k_{t+1}}{\prod_{s=1}^{t}\left(1+r_{s}\right)}=0$.
} 
Lemma 1. An allocation is implementable with proportional taxes if and only if it satisfies the implementability constraint (15) and the aggregate resource constraint (13).

Proof. See Appendix A.

\subsection{Optimal taxation}

In order to simplify notation, we denote the multiplier on the implementability constraint (15) by $\theta$ and define a pseudo utility function $W(\cdot)$ as:

$$
W\left(c_{t}, l_{t}, \theta\right) \equiv u\left(c_{t}, l_{t}\right)+\theta\left(u_{c_{t}} c_{t}+u_{l_{t}} l_{t}\right)
$$

$W\left(c_{t}, l_{t}, \theta\right)$ can be interpreted as the net social value of private utility, where the multiplier $\theta$ is a measure of aggregate tax distortions. We can then summarise the government problem:

$$
\begin{aligned}
\max _{\left\{c_{t}, l_{t}, k_{t+1}\right\}_{t=0}^{\infty}} & \sum_{t=0}^{\infty} \beta^{t} W\left(c_{t}, l_{t}, \theta\right), \\
\text { subject to } & \\
& c_{0}+g_{0}+k_{1}=f_{0}\left(l_{0}\right), \\
& c_{t}+g_{t}+k_{t+1}-(1-\delta) k_{t}=f\left(k_{t}, l_{t}\right), \quad t>0, \\
& \lim _{t \rightarrow \infty} \frac{k_{t+1}}{\prod_{s=1}^{t}\left(1+r_{s}\right)}=0 .
\end{aligned}
$$

We obtain the following first-order conditions for the government problem:

$$
\begin{aligned}
-\frac{W_{l_{t}}}{W_{c_{t}}} & =f_{l_{t}}=w_{t}, \quad t>0, \\
\frac{W_{c_{t}}}{\beta W_{c_{t+1}}} & =1+f_{k_{t+1}}-\delta=1+r_{t+1}, \quad t>0 .
\end{aligned}
$$

Equation (18) is the counterpart of the individual's first-order condition for labour supply (6). The government chooses the amount of labour in the economy until the social marginal utility cost of working $-W_{l_{t}}$ equals the social marginal benefit of working $w_{t} W_{c_{t}}$. Equation (19) is the government's Euler equation for consumption, which is the counterpart of the individual's Euler equation (7). The government chooses the consumption path such that the marginal decrease in social welfare incurred when saving in the current period $W_{c_{t}}$ is equal to the marginal increase in social welfare from consuming the proceeds of the savings in the next period $\left(1+r_{t+1}\right) W_{c_{t+1}}$.

By taking derivatives of $W$ in (16), we can find expressions for $W_{c_{t}}$ and $W_{l_{t}}$ :

$$
\begin{aligned}
& W_{c_{t}}=u_{c_{t}}\left(1+\theta+\theta\left(\frac{u_{c_{t} c_{t}} c_{t}}{u_{c_{t}}}+\frac{u_{c_{t} l_{t}} l_{t}}{u_{c_{t}}}\right)\right), \\
& W_{l_{t}}=u_{l_{t}}\left(1+\theta+\theta\left(\frac{u_{c_{t} l_{t}} c_{t}}{u_{l_{t}}}+\frac{u_{l_{t} l_{t}} l_{t}}{u_{l_{t}}}\right)\right) .
\end{aligned}
$$


We define the general-equilibrium elasticities $\varepsilon_{t}^{c}$ and $\varepsilon_{t}^{l}$ as:

$$
\begin{gathered}
-\frac{1}{\varepsilon_{t}^{c}} \equiv \frac{u_{c_{t} c_{t}} c_{t}}{u_{c_{t}}}+\frac{u_{c_{t} l_{t}} l_{t}}{u_{c_{t}}}=\frac{\partial \ln u_{c_{t}}}{\partial \ln c_{t}}+\frac{\partial \ln u_{c_{t}}}{\partial \ln l_{t}}, \\
-\frac{1}{\varepsilon_{t}^{l}} \equiv \frac{u_{c_{t} l_{t}} c_{t}}{u_{l_{t}}}+\frac{u_{l_{t} l_{t}} l_{t}}{u_{l_{t}}}=\frac{\partial \ln u_{l_{t}}}{\partial \ln c_{t}}+\frac{\partial \ln u_{l_{t}}}{\partial \ln l_{t}} .
\end{gathered}
$$

The term $\varepsilon_{t}^{c}$ captures the distortions in consumption and labour supply caused by changes in $u_{c_{t}}$, which in equilibrium equals the price of $c_{t}$. The capital income tax raises the price of consumption at date $t+1$ relative to consumption at date $t$. Hence, it induces substitution away from future consumption and future leisure towards current consumption and current leisure. The next proposition derives the optimal capital income tax in a given period $t$.

Proposition 1. The optimal linear taxes on capital and labour income in each period are, respectively:

$$
\begin{gathered}
\frac{r_{t+1} \tau_{t+1}^{K}}{1+r_{t+1}}=\frac{\theta\left(1 / \varepsilon_{t+1}^{c}-1 / \varepsilon_{t}^{c}\right)}{1+\theta-\theta / \varepsilon_{t}^{c}}, \quad t>0, \\
\frac{1}{1-\tau_{t}^{L}}=\frac{1+\theta-\theta / \varepsilon_{t}^{l}}{1+\theta-\theta / \varepsilon_{t}^{c}}, \quad t>0 .
\end{gathered}
$$

Proof. Substitute the expression for $W_{c_{t}}$ from equation (20) into the government's Euler equation (19) and use the individual's Euler equation (7) to establish the optimal capital income tax. Similarly, substitute the expressions for $W_{c_{t}}$ and $W_{l_{t}}$ from equations (20) and (21) into (18) and use the first-order conditions for the household in (5) and (6) to find the optimal labour tax.

Proposition 1 shows that taxes on capital income are desirable only if the aggregate elasticity today $\varepsilon_{t}^{c}$ is higher than the aggregate elasticity tomorrow $\varepsilon_{t+1}^{c}$. Equivalently, capital income should be taxed only if the combined distortions in consumption demand and labour supply tomorrow are lower than the combined distortions in both consumption and labour today. This conforms to standard Ramsey intuitions. In Corollary 1, we show how it is optimal to set capital income taxes to zero in the steady-state ${ }^{11}$.

Corollary 1. In the steady state, the optimal capital income tax is zero: $\tau^{K}=0$.

Proof. In the steady state, both consumption and leisure become constant, so $\varepsilon_{t}^{c}$ becomes constant. From Proposition 1, it follows that $\tau_{t}^{K}=0$ in the steady state.

\subsection{Why is the long-run tax on capital income zero?}

We argue that in the steady state, the taxation of capital income should follow the prescriptions from the literature on optimal commodity taxation. In our model, a positive tax on capital income is equivalent to taxing future consumption at a higher rate than present consumption. Similarly, a zero capital income tax is equivalent to a uniform commodity tax on consumption at

\footnotetext{
${ }^{11}$ Moreover, this result ensures that the transversality condition for government debt holds ex-post. Since $r=$ $\left(1-\tau^{K}\right) r$ when $\tau^{K}=0$, the capital market equilibrium condition (14) holds and the transversality conditions for private assets and capital hold. Hence, the transversality condition for government debt will hold automatically.
} 
different dates. Corlett and Hague (1953) show that commodity tax differentiation is generally desirable because the distortions in commodity demands help alleviate distortions in labour supply. Conversely, if differentiated commodity taxes cannot mitigate labour supply distortions, they should be uniform, in order to avoid distortions in commodity demands.

We analyze a marginal tax reform to demonstrate why capital income taxes are only useful to alleviate labour market distortions and should be set to 0 in the steady state ${ }^{12}$. The policy experiment raises the capital income tax at time $t+1$ such that consumption at time $t$ increases with $\epsilon$ and consumption at time $t+1$ declines with an amount to be yet determined. The policy experiment keeps the entire intertemporal allocation at all dates $v \neq t, t+1$ is unchanged. Hence, capital stocks at all dates $t$, except at date $t+1$, remain constant. Moreover, the policy experiment respects the implementability constraint. Therefore, taxes on labour income in period $t$ and $t+1$ adjust to ensure that the intertemporal allocation remains constant and the implementability constraint is respected. Government spending does not change. We calculate the welfare effects of this small tax perturbation and show that they are critically determined by the responses of labour supply to the capital income tax. Since the allocation for all periods except $t$ and $t+1$ does not change, raising the capital income tax in period $t+1$ only affects utility $\mathcal{W}$ in periods $t$ and $t+1$ :

$$
\mathcal{W} \equiv u\left(c_{t}, l_{t}\right)+\beta u\left(c_{t+1}, l_{t+1}\right), \quad t>0 .
$$

The next proposition derives the welfare effects of this tax perturbation.

Proposition 2. Starting from a given initial allocation, the welfare effect of marginally raising the capital income tax such that $c_{t}$ increases with $\epsilon$, while respecting the resource and implementability constraints by adjusting the taxes on labour income, is given by:

$$
\begin{aligned}
\frac{\mathrm{d} \mathcal{W}}{u_{c_{t}}} & =-\left(1-\tau_{t}^{L}\right) w_{t}\left(1-\frac{1}{\alpha_{t}}\right) \mathrm{d} l_{t}-\frac{\left(1-\tau_{t+1}^{L}\right) w_{t+1}}{\left(1+\left(1-\tau_{t+1}^{K}\right) r_{t+1}\right)}\left(1-\frac{1}{\alpha_{t+1}}\right) \mathrm{d} l_{t+1} \\
& =\left(1-\alpha_{t}\right) \epsilon-\left(\frac{1+r_{t+1}}{1+\left(1-\tau_{t+1}^{K}\right) r_{t+1}}\right)\left(\frac{1-\frac{\alpha_{t}}{1-\tau_{t}^{L}}}{1-\frac{\alpha_{t+1}}{1-\tau_{t+1}^{L}}}\right)\left(1-\alpha_{t+1}\right) \epsilon, \\
\alpha_{t} & \equiv \frac{1+\frac{c_{t} u_{c_{t} c_{t}}}{u_{c_{t}}}+\frac{l_{t} u_{l_{t} c_{t}}}{u_{c_{t}}}}{1+\frac{c_{t} u_{c_{t} l_{t}}}{u_{l_{t}}}+\frac{l_{t} u_{l_{t} l_{t}}}{u_{l_{t}}}}=\frac{1-\frac{1}{\varepsilon_{t}^{c}}}{1-\frac{1}{\varepsilon_{t}^{l}}}, \quad t>0 .
\end{aligned}
$$

Proof. The tax reform should keep the intertemporal allocation of resources constant and must be implementable with linear taxes on capital income in period $t+1$ and linear taxes on labour income in periods $t$ and $t+1$. First, this requires that the reform respects both the resource constraints in periods $t$ and $t+1$ :

$$
\begin{aligned}
f\left(\bar{k}_{t}, l_{t}\right) & =c_{t}+\bar{g}_{t}+k_{t+1}-(1-\delta) \bar{k}_{t}, \\
f\left(k_{t+1}, l_{t+1}\right) & =c_{t+1}+\bar{g}_{t+1}+\bar{k}_{t+2}-(1-\delta) k_{t+1},
\end{aligned}
$$

\footnotetext{
${ }^{12}$ See also Albanesi and Armenter (2007) who employ a similar perturbation to argue that front-loading tax distortions is desirable.
} 
where a bar indicates a variable that does not change under the reform. Second, the tax reform should respect the implementability constraints in periods $t$ and $t+1$ :

$$
c_{t} u_{c_{t}}+l_{t} u_{l_{t}}+\beta\left(c_{t+1} u_{c_{t+1}}+l_{t+1} u_{l_{t+1}}\right)=\zeta
$$

for some exogenous value $\zeta$ of the implementability constraints in all other periods $v \neq t, t+1$. Since we can adjust taxes on labour income in both period $t$ and period $t+1$ we can construct a policy reform such that the change in the implementability constraints in both period $t$ and period $t+1$ is zero by appropriate changes in the taxes on labour income:

$$
\begin{aligned}
& \mathrm{d}\left(u_{c_{t}} c_{t}+u_{l_{t}} l_{t}\right)=0, \\
& \mathrm{~d}\left(u_{c_{t+1}} c_{t+1}+u_{l_{t+1}} l_{t+1}\right)=0 .
\end{aligned}
$$

Note that if the policy experiment satisfies (32) and (33), then the implementability constraint (31) is respected.

The policy experiment raises consumption $c_{t}$ at time $t$ with $\mathrm{d} c_{t}=\epsilon$. The change in labour supply $l_{t}$ at time $t$ follows from totally differentiating the period $t$ implementability constraint (32):

$$
\mathrm{d} l_{t}=-\alpha_{t} \frac{u_{c_{t}}}{u_{l_{t}}} \mathrm{~d} c_{t}=-\alpha_{t} \frac{u_{c_{t}}}{u_{l_{t}}} \epsilon
$$

where $\alpha_{t}$ is defined in Proposition 2. By noting that $k_{t}$ is predetermined at time $t$, the change in $k_{t+1}$ is found by totally differentiating the period $t$ resource constraint (29):

$$
\mathrm{d} k_{t+1}=f_{l} \mathrm{~d} l_{t}-\mathrm{d} c_{t}=-\left(1+f_{l} \alpha_{t} \frac{u_{c_{t}}}{u_{l_{t}}}\right) \epsilon
$$

where the last part follows upon substitution of $\mathrm{d} l_{t}=-\alpha \frac{u_{c_{t}}}{u_{l_{t}}}$ and $\mathrm{d} c_{t}=\epsilon$. Similarly, the policy reform lowers consumption $c_{t+1}$ at time $t+1$. By totally differentiating the period $t+1$ implementability constraint (33), we find the change in labour $\mathrm{d} l_{t+1}$ at time $t+1$ :

$$
\mathrm{d} l_{t+1}=-\frac{u_{c_{t+1}}}{u_{l_{t+1}}} \alpha_{t+1} \mathrm{~d} c_{t+1}
$$

By differentiating the economy's resource constraint at $t+1$ in (30), we find the change in consumption $\mathrm{d} c_{t+1}$ at $t+1$ (note that $k_{t+2}$ does not change):

$$
\mathrm{d} c_{t+1}=\left(f_{k_{t+1}}+1-\delta\right) \mathrm{d} k_{t+1}+f_{l_{t+1}} \mathrm{~d} l_{t+1}=-\left(f_{k_{t+1}}+1-\delta\right)\left(\frac{1+f_{l_{t}} \frac{u_{c_{t}}}{u_{l_{t}}} \alpha_{t}}{1+f_{l_{t+1}} \frac{u_{c_{t+1}}}{u_{l_{t+1}}} \alpha_{t+1}}\right) \epsilon
$$

where the second part follows upon substitution of equations (35) and (36). Consequently, we find for $\mathrm{d} l_{t+1}$ :

$$
\mathrm{d} l_{t+1}=\frac{u_{c_{t+1}}}{u_{l_{t+1}}} \alpha_{t+1}\left(f_{k_{t+1}}+1-\delta\right)\left(\frac{1+f_{l_{t}} \frac{u_{c_{t}}}{u_{l_{t}}} \alpha_{t}}{1+f_{l_{t+1}} \frac{u_{c_{t+1}}}{u_{l_{t+1}}} \alpha_{t+1}}\right) \epsilon
$$


Totally differentiating (26) gives the change in social welfare:

$$
\mathrm{d} \mathcal{W}=u_{c_{t}} \mathrm{~d} c_{t}+u_{l_{t}} \mathrm{~d} l_{t}+\beta u_{c_{t+1}} \mathrm{~d} c_{t+1}+\beta u_{l_{t+1}} \mathrm{~d} l_{t+1}
$$

Substitute for the changes consumption using equations (34) and (36) to find:

$$
\frac{\mathrm{d} \mathcal{W}}{u_{c_{t}}}=\frac{u_{l_{t}}}{u_{c_{t}}}\left(1-\frac{1}{\alpha_{t}}\right) \mathrm{d} l_{t}+\frac{\beta u_{c_{t+1}}}{u_{c_{t}}} \frac{u_{l_{t+1}}}{u_{c_{t+1}}}\left(1-\frac{1}{\alpha_{t+1}}\right) \mathrm{d} l_{t+1} .
$$

Substituting the first-order conditions of the household in equations (5), (6) and (7) gives the first part of the proposition. Finally, we can substitute the changes in labour supply (34) and (36) into (40) and use the firm's first-order conditions in (10) and (11) to find the second part of the proposition.

Consequently, Proposition 2 recovers the Corlett-Hague motive for capital taxation in the Chamley-Judd framework. The first part of the Proposition shows how an increase in the capital income tax lowers labour supply at $t\left(\mathrm{~d} l_{t}<0\right)$ and increases labour supply at $t+1$ $\left(\mathrm{d} l_{t+1}>0\right)$. The reason for this rotation of the labour supply schedule over time is twofold, see also Jacobs and Schindler (2012). On the one hand, future leisure becomes more expensive in terms of current leisure, which leads to intertemporal substitution in leisure: labour supply in period $t+1$ increases and labour supply in period $t$ decreases. These effects are associated with the $\varepsilon_{t}^{l}$-terms. On the other hand, capital income taxes also make future consumption more expensive relative to current consumption. The corresponding substitution effect implies that consumption in period $t+1$ decreases and consumption in period $t$ increases. This latter change in consumption causes income effects in labour supply: lower consumption in period $t+1$ implies that labour supply in period $t+1$ increases, while higher consumption in period $t$ implies that labour supply in period $t$ decreases. These effects are associated with the $\varepsilon_{t}^{c}$-terms. If the increase (decrease) in labour supply at time $t+1(t)$ is sufficiently large (small), social welfare increases $(\mathrm{d} \mathcal{W}>0)$. Consequently, the increase in the capital income tax is socially desirable.

The $\alpha_{t}$-terms $\left(\alpha_{t}=\left(1-1 / \varepsilon_{t}^{c}\right)\left(1-1 / \varepsilon_{t}^{l}\right)^{-1}\right)$ capture the complementarity between consumption and labour. If $\alpha_{t+1}<\alpha_{t}$, consumption at date $t+1$ is less complementary with labour in periods $t$ and $t+1$ than consumption at date $t$. Consequently, introducing a capital income tax is socially desirable, provided there is no initial capital income taxation (i.e., $\tau_{t+1}^{K}=0$ ) and labour taxes are constant over time (i.e., $\tau_{t}^{L}=\tau_{t+1}^{L}$ ). If there is a positive pre-existing capital income tax $\left(\tau_{t+1}^{K}>0\right)$, increasing it further is socially desirable only if the benefits of reduced labour market distortions are still larger than the costs of larger saving distortions. Clearly, if labour taxes are not constant over time, intertemporal labour supply decisions are distorted. Then, the capital income tax can either alleviate or exacerbate the intertemporal labour market distortions generated by non-constant labour taxes. The latter finding has not yet received a lot of attention in the literature: zero optimal capital taxation generally requires constant labour taxes. If, for whatever reason, labour taxes are not constant, optimal capital income taxes need not be zero.

To further illustrate the Corlett-Hague motive, we can analyze the welfare effect of intro- 
ducing a small capital income tax in a setting with constant labour taxation $\left(\tau_{t}^{L}=\tau_{t+1}^{L}=\tau^{L}\right)$ and no initial capital income taxation $\left(\tau_{t+1}^{K}\right)$. Using equation (27), it follows that the welfare effect of such a reform is:

$$
\frac{\mathrm{d} \mathcal{W}}{u_{c_{t}}}=\frac{\left(\alpha_{t}-\alpha_{t+1}\right) \tau^{L}}{1-\tau^{L}-\alpha_{t+1}} \epsilon, \quad t>0 .
$$

Thus, the introduction of a capital income tax is socially desirable only if consumption at date $t+1$ is less complementary to labour than consumption at date $t$, i.e., if $\alpha_{t+1}<\alpha_{t}$.

Proposition 2 governs the desirability of capital income taxation even if the economy has not converged to a steady state. In the steady state, $c, l$ and $k$ are all constant, which renders $\alpha, f_{k}, f_{l}, u_{c}$ and $u_{l}$ constant. If labour taxes are constant, we can use equation (27) to calculate the welfare effect of introducing a small capital income tax in the steady state:

$$
\frac{\mathrm{d} \mathcal{W}}{u_{c}}=-\frac{(1-\alpha) \tau_{K} r}{1+\left(1-\tau^{K}\right) r} \epsilon<0
$$

Introducing a small capital income tax in a steady state with constant labour taxes unambiguously lowers social welfare: the increase in distortions from lower current labour supply is larger than the decrease in distortions in future labour supply. The implication is clear: capital income taxes are not desirable, so they should be zero in the steady state.

The following Corollary demonstrates that the optimal capital income tax derived under the perturbation approach is exactly the same as the optimal capital income tax derived in Proposition 1, provided labour income taxes are optimised. Thus, the perturbation approach leads to the same solution as the primal approach.

Corollary 2. If labour taxes are optimized according to (25), the perturbation approach gives the following optimal capital income tax:

$$
\frac{r_{t+1} \tau_{t+1}^{K}}{1+r_{t+1}}=\frac{\theta\left(1 / \varepsilon_{t+1}^{c}-1 / \varepsilon_{t}^{c}\right)}{1+\theta-\theta / \varepsilon_{t}^{c}}, \quad t>0
$$

Proof. In the optimum, the marginal benefits and the marginal costs of the reform should cancel out, so $\mathrm{d} \mathcal{W}=0$ in equation (27). Rewriting that expression, we obtain:

$$
\frac{1+\left(1-\tau_{t+1}^{K}\right) r_{t+1}}{1+r_{t+1}}=\frac{1-\frac{\alpha_{t}}{1-\tau_{t}^{L}}}{1-\frac{\alpha_{t+1}}{1-\tau_{t+1}^{L}}} \frac{1-\alpha_{t+1}}{1-\alpha_{t}}
$$

Substituting $\alpha_{t}$ and $\alpha_{t+1}$ from equation (28) and $\tau_{t}^{L}$ and $\tau_{t+1}^{L}$ from the optimal labor income tax expression in equation (25), we obtain the the optimal capital income tax $\tau_{t+1}^{K}$ :

$$
\frac{r_{t+1} \tau_{t+1}^{K}}{1+r_{t+1}}=\frac{\theta\left(1 / \varepsilon_{t+1}^{c}-1 / \varepsilon_{t}^{c}\right)}{1+\theta-\theta / \varepsilon_{t}^{c}}
$$

The expression above is identical to the expression obtained using the primal approach in equation (24). 


\subsection{Relation to commodity tax literature}

Our findings can also be related to the optimal commodity tax literature. Sandmo (1974) and Deaton (1979) have shown that if the government can only employ linear taxes and Engel curves of all commodities are linear in labour earnings, differentiated commodity taxation cannot alleviate labour supply distortions. The intuition is straightforward: if Engel curves are linear, commodity taxes impose the same distortions on labour supply, but in addition distort saving. The latter distortions can be avoided by only taxing labour income and setting uniform commodity taxes. The next proposition demonstrates that indeed Engel curves become linear in the steady state.

Proposition 3. In the steady state, the Engel curves for consumption become linear in labour earnings irrespective of assumptions on preferences:

$$
c=\frac{a}{\beta}+\left(1-\tau^{L}\right) w l
$$

Proof. Suppose that the economy is in a steady state from time $t=T$ onwards. Iterating the individual budget constraint (2) forward from period $T$ onwards and applying the transversality condition on private assets (3), we obtain the lifetime budget constraint from time $T$ onwards:

$$
\sum_{t=T}^{\infty} \frac{c_{t}}{\prod_{s=T}^{t}\left(\left(1+\left(1-\tau_{s}^{K}\right) r_{s}\right)\right.}=a_{T}+\sum_{t=T}^{\infty} \frac{\left(1-\tau_{t}^{L}\right) w_{t} l_{t}}{\prod_{s=T}^{t}\left(\left(1+\left(1-\tau_{s}^{K}\right) r_{s}\right)\right.}
$$

If the economy has settled in a steady state from period $T$ onwards, consumption $c_{t}$, labour $l_{t}$, assets $a_{t}$ and prices $\left(1-\tau_{t}^{K}\right) r_{t}$ and $\left(1-\tau_{t}^{L}\right) w_{t}$ are all constant for $t \geq T$. Moreover, in order to ensure the existence of a steady state, the rate of time preference needs to be equal to the inverse of the discount rate, so $\beta=\frac{1}{1+\left(1-\tau^{K}\right) r} 13$. This means that in each period of the steady state, the individual budget constraint (47) becomes:

$$
c=\left(1-\tau^{K}\right) r a+\left(1-\tau^{L}\right) w l \Leftrightarrow c=\frac{a}{\beta}+\left(1-\tau^{L}\right) w l .
$$

The steady-state assumption forces all consumption Engel curves to become linear in labour earnings, so an increase in $w l$ leads to a proportional increase in consumption $c$. Therefore, consumption at all dates becomes equally complementary to labour supply at date $t$ and $t+1$, as we have shown above. Consequently, a capital income tax in the form of a linear tax on savings generates the same labour supply distortions as a revenue-equivalent linear tax on labour earnings. However, capital income taxes also cause distortions in saving behaviour, which can be avoided by levying only taxes on labour income. The zero capital income tax is thus found for all utility functions and not only weakly separable and homothetic ones.

Lemma 2 shows that if preferences are separable between consumption and leisure and homothetic in the consumption sub-utility, $\varepsilon_{t}^{c}$ is constant in all periods, not just in the steady state.

\footnotetext{
${ }^{13}$ This result is obtained if one keeps $c_{t}$ constant in the Euler equation (7).
} 
Lemma 2. If the utility function is additively time-separable, strongly separable between consumption and labour and homothetic in the consumption sub-utility, then $\varepsilon_{t}^{c}$ is constant and capital income taxes are optimally zero at all dates.

Proof. See Chari and Kehoe (1999) and Appendix B.

Equation (22) shows how the assumptions of separability and homotheticity lead to a constant general equilibrium elasticity $\varepsilon_{t}^{c}$. If the utility function is separable between consumption and labour, $u_{c l}=0$ and the second term in equation (22) is zero. Furthermore, if the consumption sub-utility is homothetic, the first term of equation (22) becomes a constant. The combination of these two properties renders $\varepsilon_{t}^{c}$ constant. Thus, the same kind of properties of the utility function that lead to linear Engel curves in the static settings of Sandmo (1974) and Deaton (1979) render capital income taxes redundant in the dynamic setting of Chamley-Judd. Intuitively, since the Engel curves are linear, consumption is equally complementary to leisure in every period, making capital income taxes redundant in every period and not only in the steady-state.

Deaton (1979) showed that optimal commodity taxes are uniform if the utility function has the Gorman (1961) polar form. This class of utility functions includes, among others, CES, Cobb-Douglas, Stone-Geary and iso-elastic utility. If utility is of the Gorman polar form, consumption Engel curves are linear, but do not necessarily pass through the origin. As a result, a non-individualised lump-sum tax is necessary to obtain optimally uniform commodity taxes. This instrument is allowed for in Deaton (1979), since he analyzes a model with heterogeneous agents. However, we cannot generalize Lemma 2 to Gorman polar preferences, since lump-sum taxes are ruled out in our representative-agent framework. Consequently, the consumption subutility needs to be homothetic in order to obtain zero optimal capital income taxes at all dates. In that case, consumption Engel curves are linear and also pass through the origin, so capital income taxes generate the same labour market distortions as labour income taxes. Since capital income taxes cannot alleviate labour market distortions and only distort consumption choices, they are optimally set to zero at all times.

\section{Interpretations in the literature}

The optimal taxation literature discusses two main economic intuitions that would explain the Chamley-Judd result that the tax on capital income should be zero in the long run. The first is that a non-zero capital income tax results in exploding tax distortions in finite time, which violates the Ramsey principle to smooth distortions over time, see also Judd (1999) and Banks and Diamond (2010). The second intuition is that if the supply of capital is infinitely elastic in the long run, all taxes are borne by labour in any case. Hence, it is better not to distort capital accumulation by setting a zero tax on capital income, see also Auerbach and Kotlikoff (1983), Correia (1996), Mankiw, Weinzierl, and Yagan (2009) and Piketty and Zucman (2014). This section argues that the first intuition can be interpreted as a special case of our generalized Corlett-Hague intuition and the second intuition is misleading. 


\subsection{Intuition 1: exploding tax distortions}

Can the Chamley-Judd results be interpreted as a strict application of the Ramsey principle, as in Judd (1999) and Banks and Diamond (2010)? In this section, we show how the Ramsey intuition of taxing inelastic consumption demands at higher rates can be seen as a special case of the Corlett-Hague intuition which calls for taxing leisure complements at higher rates (Corlett and Hague, 1953). Moreover, the Chamley-Judd result can be seen as an application of the Ramsey principle only when restrictive assumptions are made on the utility function.

We can gain more intuition as to how the standard mechanisms from the static models of the optimal taxation literature apply to the dynamic model developed in this paper. We can measure the complementarity between consumption at period $t$ and leisure at period $j$ by $\varepsilon_{c_{t} w_{j}^{*}}^{*}$, which is the compensated elasticity of consumption $c_{t}$ with respect to the net wage $w_{j}^{*} \equiv\left(1-\tau_{j}^{L}\right) w_{j}$ in period $j$, see also Atkinson and Stiglitz (1980). A compensated increase in the net wage $w_{j}^{*}$ leads to an increase in labour $l_{j}$, or alternatively, a decrease in leisure $1-l_{j}$. If $\varepsilon_{c_{t+1} w_{j}^{*}}^{*}>\varepsilon_{c_{t} w_{j}^{*}}^{*}$, then the increase in $w_{j}$ leads to a larger increase in $c_{t+1}$ than in $c_{t}$. This implies that $c_{t+1}$ is more complementary to labour than $c_{t}$ or, equivalently, $c_{t+1}$ is less complementary to leisure than $c_{t}$ in the Corlett-Hague sense. Similarly, we define the the compensated price elasticity of consumption with respect to the net interest rate $r_{j}^{*} \equiv\left(1-\tau_{j}^{K}\right) r_{j}$ in period $j$ as $\varepsilon_{c_{t}}^{*} r_{j}$. In Proposition 4, we show that if consumption demands depend solely on contemporaneous prices, i.e. the net interest rate and wage rate in that period, the goods that are less price elastic are also the consumption goods that are relatively more complementary to leisure.

Proposition 4. Assume that there exists a final time period T. If consumption demands depend only on prices in period $t$, and consumption in period $t$ is more elastic with respect to the net interest rate than consumption in period $t+1$, so that $\varepsilon_{c_{t} r_{t}^{*}}^{*}>\varepsilon_{c_{t+1} r_{t+1}^{*}}^{*}$, then consumption in period $t$ is also more complementary to leisure than consumption in period $t+1$, i.e., $\varepsilon_{c_{t} w_{t}^{*}}^{*}<$ $\varepsilon_{c_{t+1} w_{t+1}^{*}}^{*}$, since $\varepsilon_{c_{t} r_{t}^{*}}^{*}+\varepsilon_{c_{t} w_{t}^{*}}^{*}=0$.

Proof. Assume that there exists a final time period, $T$. This allows us to inspect the individual's expenditure minimisation problem, where the individual chooses consumption and leisure to minimise the lifetime income that attains utility $\bar{U}$. The individual's dual problem becomes:

$$
\begin{aligned}
& \min _{\left\{c_{t}, l_{t}\right\}_{t=0}^{T}} c_{0}+w_{0}^{*}\left(1-l_{0}\right)+\sum_{t=1}^{T} \frac{c_{t}+w_{t}^{*}\left(1-l_{t}\right)}{\prod_{s=1}^{t}\left(1+r_{s}^{*}\right)}, \\
& \text { subject to } U\left(c_{0}, \ldots, c_{T}, l_{0}, \ldots, l_{T}\right) \geq \bar{U}
\end{aligned}
$$

Solving the problem above leads to compensated demands $\left\{c_{t}^{*}, l_{t}^{*}\right\}_{t=0}^{T}$, which are homogeneous of degree 0 :

$$
y_{t}\left(r_{1}^{*}, \ldots, r_{T}^{*}, w_{0}^{*}, \ldots, w_{T}^{*}\right)=y_{t}\left(\phi r_{1}^{*}, \ldots, \phi r_{T}^{*}, \phi w_{0}^{*}, \ldots, \phi w_{T}^{*}\right), \quad \phi>0, \quad y_{t}=\left\{c_{t}, l_{t}\right\}
$$

We can differentiate this equation with respect to $\phi$, set $\phi$ to 1 , and define $\varepsilon_{y_{t} p_{j}}^{*}$ as the compensated elasticity of period $t$ good $y_{t}=\left\{c_{t}, l_{t}\right\}$ with respect to perid $j$ price $p_{j}=\left\{r_{j}^{*}, w_{j}^{*}\right\}$. This 
leads to:

$$
\sum_{j=1}^{T} \varepsilon_{c_{t} r_{j}^{*}}^{*}+\sum_{j=0}^{T} \varepsilon_{c_{t} w_{j}^{*}}^{*}=0
$$

If we assume that consumption elasticities solely depend on prices in period $t$, this expression collapses to the proposition.

In order to prove Proposition 4, we assumed the existence a final period $T$. This is a technical assumption that ensures we can analyse the individual's dual problem without focusing on the issue of infinite commodity spaces. The result in Proposition 4 is valid for an arbitrarily large $T$, so the assumption of finite time should not obscure the relevance of the Proposition.

Thus, Proposition 4 shows that if consumption demands solely depend on contemporaneous prices, a good that is very elastic with respect to its own price will also be very complementary to leisure: thus high elasticities of consumption with respect to net interest rates $\varepsilon_{c_{t} r_{j}^{*}}^{*}$ mean low compensated elasticities of consumption with respect to net wage rates $-\varepsilon_{c_{t} w_{t}^{*}}^{*}$ and vice versa. Consequently, the Ramsey inverse-elasticity rule is nested as a special case of the general Corlett-Hague rule for commodity taxation. This can also be seen from the definition of the general-equilibrium elasticity $\varepsilon_{t}^{c}$ in equation (22). Naturally, if the utility function is separable, so that $u_{c l}=0$ in equation (22), the Ramsey intuition is applicable. In this pure Ramsey case, capital income is taxed only if the elasticity of marginal utility of consumption $\left(\frac{\partial \ln c_{t}}{\partial \ln u_{c_{t}}}\right)^{-1}$ varies with time.

However, the standard Ramsey intuition - that inelastic goods should be taxed at higher rates - need not always be applicable: the Ramsey explanation critically depends on the assumption that compensated demands for goods depend solely on contemporaneous prices. If compensated demands also depend on other prices, it is theoretically possible to have a good that is both inelastic with respect to its own price and is complementary to labour at the same time. In that case, it could be that the complementarity is so strong that it becomes optimal to subsidise the good to reduce labour supply distortions. To see why, in the general case the general-equilibrium elasticity $\varepsilon_{t}^{c}$ includes complementarities with labour, i.e. $\frac{\partial \ln l_{t}}{\partial \ln u_{c_{t}}}$ that are not present in the own-price elasticities, i.e., $\frac{\partial \ln c_{t}}{\partial \ln u_{c_{t}}}$. By distorting the consumption prices, the capital income tax not only distorts the intertemporal allocation of consumption, but also affects the intertemporal allocation of labour supply. Given that labour supply is distorted by the labour income tax, a capital income tax (or a subsidy) can be helpful to reduce labour supply distortions. This depends on the specific pattern of $\frac{\partial \ln l_{t}}{\partial \ln u_{c_{t}}}$ over time and no general conclusion can be drawn about this term without imposing further structure on the utility function.

\subsection{No convergence to steady state needed?}

Our analysis so far suggests that capital income taxes are optimally zero in a limited array of cases: if the economy is in a steady-state, or if preferences are restricted to a specific class. However, Judd (1999) argues that under any utility function, distortions arising from capital income taxation would explode in finite time. Thus, the optimal tax on capital income would be driven down to zero as the deadweight loss of taxation would reach an upper bound in finite time. Hence, the optimal tax on capital income is zero in finite time even if the economy does 
not converge to a steady-state. This finding seems to suggest that no restrictions on the utility function are needed to obtain a zero tax on capital income in finite time.

However, Judd (1999) does not take into account that taxes on capital income may be desirable to alleviate the distortions of taxes on labour income on labour supply. While the wedge between the MRS and MRT between consumption at early periods and future consumption can indeed grow at an exponential rate if capital income is taxed, this can be optimal if labour supply distortions would also grow exponentially over time. Hence, one cannot a priori conclude that capital income taxes should converge to zero in finite time ${ }^{14}$. From the models with a finite time horizon, we know that the Corlett-Hague motive is generally always present unless restrictions are imposed on the utility function, see for example Atkinson and Sandmo (1980) and Erosa and Gervais (2002).

Moreover, the analysis of Judd (1999) also reveals that the deadweight loss of taxation becomes constant in finite time only if the general-equilibrium elasticity $\varepsilon_{t}^{c}$ converges to a constant in finite time, see his equation (28). Hence, his argument that distortions would reach an upper bound is equivalent to making the assumptions of separability between consumption and leisure and homotheticity of the consumption sub-utility, which, as we showed in Lemma 2, would eliminate the Corlett-Hague motive for capital income taxation. Corollary (12) of Judd (1999) demonstrates that if the assumptions of separability between consumption and leisure and homotheticity of the consumption sub-utility are violated, the optimal tax on capital income is not zero if the steady-state is not reached. In particular, assuming a Stone-Geary utility function that is separable between consumption and labour, Judd (1999) concludes that "the capital income tax is never zero, but for reasons which are consistent with the inverse-elasticity rule", i.e. the Ramsey rule. In this case, the term $\frac{\partial \ln c_{t}}{\partial \ln u_{c_{t}}}$ in equation (22) is never constant and $u_{c l}$ equals 0 . Thus, without invoking the steady-state assumption, or without assuming separable and homothetic preferences, the capital income tax rate fluctuates according to the inverse of the elasticity of consumption, i.e., according to whether consumption is more or less complementary to leisure over time.

Straub and Werning (2014) show that the results of Judd (1999) need a large qualification, as the latter assumes that the multipliers of the government's budget constraint, which are are endogenous, are bounded. Judd (1999) then concludes that the steady-state is not required to obtain a zero capital income tax: the result holds in finite time, as long as the bound on the multipliers holds. We agree with the qualifications raised by Straub and Werning (2014). However, we take their argument further: we look at the case where this bound is not required, so that the analysis of Judd (1999) is valid. In that case, the assumptions on preferences that Judd (1999) makes are equivalent to the Corlett-Hague motive vanishing, thus reinforcing our results.

To conclude, the standard Ramsey intuition applied in Judd (1999) and Banks and Diamond (2010) need not always be applicable: this critically depends on the general-equilibrium elasticity $\varepsilon_{t}^{c}$ converging to a constant, which either requires specific assumptions on the utility function (namely, separability between consumption and leisure and homotheticity of the consumption

\footnotetext{
${ }^{14}$ A similar argument is put forward in Straub and Werning (2014), who show that the ratio of the marginal costs and benefits of taxation remains constant. This suggests that discussing only the costs of taxation does not give a complete picture of the trade-offs faced by the government.
} 
sub-utility) or convergence to a steady state.

\subsection{Non-separable utility}

So far, we focused solely on optimal capital income taxation if utility is additively separable with respect to time. A natural question then arises: how should capital income be taxed if utility is not time-separable? Straub and Werning (2014) showed the importance of the assumption of time separability in the analysis of Chamley (1986). If the individual utility function is not time-separable, convergence to a steady-state is unlikely and, even if it occurs, the steady-state features either zero private wealth or a first-best result. In such cases, it can be optimal to indefinitely tax capital income at the maximum rate. Since first-best outcomes are unlikely to occur in practice and 100\% capital income taxes are not implementable in market economies, the results obtained by Straub and Werning (2014) with non-additive utility are mostly of theoretical interest.

Our main intuitions nevertheless carry over to the non-separable case. The next Lemma shows the conditions necessary for the capital income taxes to be zero if preferences are not timeseparable and the individual faces a finite horizon. No steady-state assumptions are invoked here.

Lemma 3. If the agent faces a finite horizon $0<t \leq T$, and preferences are of the form:

$$
U=U\left(h\left(c_{0}, \ldots, c_{T}\right), v\left(l_{0}, \ldots, l_{T}\right)\right)
$$

with $h(\cdot)$ and $v(\cdot)$ denoting homothetic sub-utility functions, then the capital income taxes are optimally zero in every period.

Proof. See Appendix C.

If utility is weakly separable between consumption and leisure and homothetic both in consumption and leisure, there is no scope for capital income taxes. The intuition for the result is the same as in the time-separable case: the weak separability and homotheticity of the utility function lead to linear Engel curves. Thus, present and future consumption are equally complementary to leisure, rendering capital income taxes ineffective for alleviating labour supply distortions.

\subsection{Intuition 2: full tax shifting to labour}

Another common explanation for the zero optimal capital income tax result can be found in the work of Auerbach and Kotlikoff (1983), Correia (1996), Mankiw, Weinzierl, and Yagan (2009) and Piketty and Zucman (2014). These authors assert that the supply of capital becomes infinitely elastic in the long run, so that the entire burden of a tax on capital income is borne by labour. Since in the long run the net interest rate is fixed by exogenous factors - such as the rate of time preference and depreciation - any decrease due to taxing capital income will be perfectly offset by a one-to-one increase in the gross interest rate. In this section, we show that this mechanism cannot be the driving force behind the Chamley-Judd result. We do so by switching off the general-equilibrium effects on the interest rate and considering the case of an 
open economy. Since the gross interest rate is fixed in the world asset markets, the tax burden on capital cannot be shifted towards labour through general-equilibrium effects on factor prices.

To fix ideas, the representative individual and the government are allowed to access a perfectly competitive international capital market in which a foreign asset $x_{t}$ is traded. Foreign capital $x_{t}$ is supplied infinitely elastically and yields an exogenously given return $r_{t}$, which is the required return for private debt $a_{t}$ and government debt $d_{t}$. The government and the representative individual have optimisation problems that are identical to closed-economy case, with the only difference that now both have access to the international capital market. Moreover, the implementability constraint remains identical to the one derived in (15).

The main difference with the closed-economy set-up is the assumption that the production technology $f(\cdot)$ employs only labour: $f\left(l_{t}\right)=A_{t} l_{t}$. This way, we sever the link between wages and interest rates, while keeping everything else identical with the closed-economy setting. Profit maximisation then implies that labour demand is perfectly elastic at the market wage: $A_{t}=w_{t}$.

In this open economy, total domestic production $w_{t} l_{t}$ need not equal domestic absorption $c_{t}+g_{t}$. Hence, the current account is determined by:

$$
\begin{aligned}
c_{t}+g_{t}+x_{t+1}-\left(1+r_{t}\right) x_{t} & \leq w_{t} l_{t}, \quad t \geq 0, \\
\lim _{t \rightarrow \infty} \frac{x_{t+1}}{\prod_{s=1}^{t}\left(1+r_{s}\right)} & =0 .
\end{aligned}
$$

To prevent explosive paths of net foreign debt, we impose a no-Ponzi-game condition: current account deficits are always repaid with later current account surpluses.

The capital market equilibrium condition in the open economy is similar to the one in the closed-economy model in Section 2:

$$
a_{t}-d_{t}=x_{t}, \quad t>0 .
$$

The left-hand side represents the demand for foreign capital: both the individual and the government demand assets in their intertemporal trades. The right-side of the equation represents the total supply of capital: foreign capital flows into the economy, which increases the intertemporal consumption possibilities compared to the case when the economy is closed.

Since the domestic firm does not employ capital in its production process, we need to modify the definition of an implementable allocation to include the flows of foreign investment $x_{t}$ instead of $k_{t}$, see Definition 2 .

Definition 2. An allocation $\left\{c_{t}, g_{t}, x_{t+1}\right\}_{t=0}^{\infty}$ is implementable with proportional taxes on capital and labour income, given the factor prices $\left\{w_{t}, r_{t}\right\}_{t=0}^{\infty}$, if it satisfies the following conditions:

- There exists the sequence of taxes $\left\{\tau_{t+1}^{K}, \tau_{t}^{L}\right\}_{t=0}^{\infty}$ and a sequence of asset holdings $\left\{a_{t+1}\right\}_{t=0}^{\infty}$ such that the allocation solves the individual's problem, given the prices;

- The allocation satisfies the government budget constraint (8) every period;

- The allocation satisfies the aggregate resource constraint (53) every period; 
- The allocation satisfies the domestic capital market equilibrium (55) every period.

Lemma 4 is the counterpart of Lemma 1 in an open-economy setting. It shows that for an allocation to be implementable with proportional taxes in an open-economy setting, it need only be feasible (satisfy the aggregate resource constraint (53)) and satisfy the implementability constraint (15).

Lemma 4. An allocation $\left\{c_{t}, g_{t}, x_{t+1}\right\}_{t=0}^{\infty}$ is implementable with proportional taxes on capital and labour income, given the factor prices $\left\{w_{t}, r_{t+1}\right\}_{t=0}^{\infty}$, if and only if it satisfies the implementability constraint (15) and the aggregate resource constraint (53).

Proof. See Appendix D.

Thus, if we denote by $\theta$ the multiplier on the implementability constraint (15) and define the modified welfare function as we did in the closed-economy case in equation (16), the optimisation problem of the government becomes:

$$
\begin{aligned}
\max _{\left\{c_{t}, g_{t}, x_{t+1}\right\}_{t=0}^{\infty}} & \sum_{t=0}^{\infty} \beta^{t} W\left(c_{t}, l_{t}, \theta\right) \\
\text { subject to } & w_{t}, r_{t} \text { given, } \quad \forall t, \\
& c_{t}+g_{t}+x_{t+1}-\left(1+r_{t}\right) x_{t}=w_{t} l_{t}, \quad \forall t, \\
& \lim _{t \rightarrow \infty} \frac{x_{t+1}}{\prod_{s=1}^{t}\left(1+r_{s}\right)}=0 .
\end{aligned}
$$

From this formulation it is obvious that the optimal tax problem in the open-economy setting is mathematically identical to the closed-economy setting. The only difference is cosmetic: the government chooses the amount of private domestic capital $k_{t+1}$ in the closed economy and the amount of foreign capital $x_{t+1}$ in the open economy. We thus confirm Diamond and Mirrlees (1971): optimal tax expressions are identical the open economy with constant factor prices and in the closed economy with endogenous factor prices $^{15}$. As a result, the steady-state optimal capital income tax expression will still lead to the Chamley (1986) and Judd (1985) result: $\tau^{K}=0^{16}$. Note that in the open economy, the real interest rate $r$ is constant. Hence, a steady state only exists if an assumption is made on the discount factor $\beta$. In particular, the discount factor $\beta$ must be must be consistent with the individual Euler condition in the steady-state (7): $\beta=\left[1+\left(1-\tau^{K}\right) r\right]^{-1}$.

One may wonder, then, to what extent the assumption on the discount rate assumes the zero tax on capital income? This turns out not to be the case. The government's Euler equation (19), together with the private Euler equation (7), simultaneously determine $\beta$ and $\tau^{K}$. These are two equations in two unknowns. This means that the open-economy assumption, i.e. fixing the gross interest rate, does not assume the zero tax result. In the open economy, the private Euler equation pins down a value for the discount rate $\beta$ that is consistent with a steady state

\footnotetext{
${ }^{15}$ We should note that the production efficiency theorem relies on the absence of pure profits (or the availability of a perfect profit tax) and full verifiability of all transactions between firms and households (Diamond and Mirrlees, 1971). Our model satisfies both requirements.

${ }^{16}$ This result depends on the absence of pure profits (constant returns to scale in production) or the presence of a pure profit tax when returns to scale are not constant. See also Correia (1996).
} 
for any net interest rate (i.e., for any capital income tax $\tau^{K}$, including a zero capital income tax). One then needs the government Euler equation to prove that the optimal capital income tax is indeed zero in the steady state ${ }^{17}$.

We have demonstrated that the optimal long-run capital income tax is zero both in openeconomy and in closed-economy settings. This finding is not consistent with the notion that in the long run, the capital income tax is completely shifted to labour via general-equilibrium effects on interest rates and wages, as the latter are absent - by definition - in our open-economy setting.

\section{Conclusion}

This paper tried to answer the question: why is the long-run capital income tax zero in Chamley (1986) and Judd (1985)? We demonstrated that standard principles from the optimal commodity tax literature drive the result that capital income taxes should be zero. In particular, the steady-state assumption forces the consumption Engel curves to become linear in labour earnings. This holds true even if preferences are non-separable between consumption and leisure and non-homothetic in consumption. Hence, consumption at different dates becomes equally complementary with leisure. This means that capital income taxes cannot be used to offset the labour supply distortions cause by labour income taxes.

Moreover, the argument that a positive capital income tax would lead to exploding tax distortions in finite time needs reconsideration, as this intuition is applicable only when restrictions are made on the utility function. We show these restrictions are identical to the restrictions required to have no commodity tax differentiation. We also argue that general-equilibrium effects on interest rates cannot be the main driver behind the long-run zero optimal capital income tax, since we found that the optimal capital income tax is zero also in an open-economy setting, where interest rates are constant.

\section{References}

Albanesi, Stefania and Roc Armenter. 2007. "Understanding Capital Taxation in Ramsey Models." mimeo: Columbia University and Federal Reserve Bank New York.

Atkinson, Anthony B. and Agnar Sandmo. 1980. "Welfare Implications of the Taxation of Savings." Economic Journal 90 (359):529-49.

Atkinson, Anthony B. and Joseph E. Stiglitz. 1976. "The Design of Tax Structure: Direct versus Indirect Taxation." Journal of Public Economics 6 (1-2):55-75.

1980. Lectures on Public Economics. London and New York: McGraw-Hill.

Auerbach, Alan J. and Laurence J. Kotlikoff. 1983. "National Savings, Economic Welfare,

\footnotetext{
${ }^{17}$ Similarly, in the closed economy the discount rate $\beta$ is given and the interest rate $r$ is endogenous. The private and government Euler equations then jointly determine the steady state gross interest rate $r$ and the optimal capital income $\operatorname{tax} \tau^{K}$.
} 
and the Structure of Taxation." In Behavioral Simulation Methods in Tax Policy Analysis. National Bureau of Economic Research, 459-498.

Banks, James and Peter A. Diamond. 2010. "The Base for Direct Taxation." In The Mirrlees Review. Dimensions of Tax Design, edited by James A. Mirrlees et al., chap. 6. Oxford: Oxford: Oxford University Press, 548-648.

Chamley, Christophe. 1986. "Optimal Taxation of Capital Income in General Equilibrium with Infinite Lives." Econometrica 54 (3):607-622.

Chari, V.V. and Patrick J. Kehoe. 1999. "Optimal Fiscal and Monetary Policy." In Handbook of Macroeconomics, Handbook of Macroeconomics, vol. 1, edited by John B. Taylor and Michael Woodford, chap. 26. Elsevier, 1671-1745.

Corlett, Wilfred J. and Douglas C. Hague. 1953. "Complementarity and the Excess Burden of Taxation." Review of Economic Studies 21 (1):21-30.

Correia, Isabel H. 1996. "Should Capital Income be Taxed in the Steady State?" Journal of Public Economics 60 (1):147-151.

Deaton, Angus. 1979. "Optimally Uniform Commodity Taxes." Economics Letters 2 (4):357361.

Diamond, Peter A. and James A. Mirrlees. 1971. "Optimal Taxation and Public Production I: Production Efficiency." American Economic Review 61 (1):8-27.

Diamond, Peter A. and Emmanuel Saez. 2011. "The Case for a Progressive Tax: From Basic Research to Policy Recommendations." Journal of Economic Perspectives 25 (4):165-190.

Erosa, Andrès and Martin Gervais. 2002. "Optimal Taxation in Life-Cycle Economies." Journal of Economic Theory 105 (2):338-369.

Fischer, Stanley. 1980. "Dynamic Inconsistency, Cooperation, and the Benevolent Dissembling Government." Journal of Economic Dynamics and Control 2:93-107.

Gorman, William M. 1961. "On a Class of Preference Shields." Metroeconomica 13 (2):53-56.

Jacobs, Bas. 2013. "From Optimal Tax Theory to Applied Tax Policy." FinanzArchiv $69(3): 338-389$.

Jacobs, Bas and Robin Boadway. 2014. "Optimal linear commodity taxation under optimal non-linear income taxation." Journal of Public Economics 117 (C):201-210.

Jacobs, Bas and Dirk Schindler. 2012. "On the Desirability of Taxing Capital Income in Optimal Social Insurance." Journal of Public Economics 96 (9-10):853-868.

Jones, Larry E., Rodolfo E. Manuelli, and Peter E. Rossi. 1997. "On the Optimal Taxation of Capital Income." Journal of Economic Theory 73 (1):93 - 117. 
Judd, Kenneth L. 1985. "Redistributive Taxation in a Simple Perfect Foresight Model." Journal of Public Economics 28 (1):59-83.

. 1999. "Optimal Taxation and Spending in General Competitive Growth Models." Journal of Public Economics 71 (3):1-26.

Krusell, Per, Burhanettin Kuruşçu, and Anthony A. Smith. 2010. "Temptation and Taxation." Econometrica 78 (6):2063-2084.

Kydland, Finn E. and Edward C. Prescott. 1977. "Rules Rather than Discretion: The Inconsistency of Optimal Plans." Journal of Political Economy 85 (3):473-492.

Ljungqvist, Lars and Thomas J. Sargent. 2004. Recursive Macroeconomic Theory. CambridgeMA: MIT-Press.

Mankiw, N. Gregory, Matthew C. Weinzierl, and Danny Yagan. 2009. "Optimal Taxation in Theory and Practice." Journal of Economic Perspectives 23 (4):147-174.

Mirrlees, James A., Stuart Adam, Timothy J. Besley, Richard Blundell, Steven Bond, Robert Chote, Malcolm Gammie, Paul Johnson, Gareth D. Myles, and James M. Poterba. 2011. Tax by Design: The Mirrlees Review. Oxford: Oxford University Press.

Ordover, Janusz A. and Edmund S. Phelps. 1979. "The Concept of Optimal Taxation in the Overlapping-Generations Model of Capital and Wealth." Journal of Public Economics $12(1): 1-26$.

Piketty, Thomas and Gabriel Zucman. 2014. "Capital is Back: Wealth-Income Ratios in Rich Countries, 1700-2010." Quarterly Journal of Economics 129 (3):1255-1310.

Ramsey, Frank P. 1927. "A Contribution to the Theory of Taxation." Economic Journal 37 (145):47-61.

Sandmo, Agnar. 1974. "A Note on the Structure of Optimal Taxation." American Economic Review 64 (4):701-706.

Straub, Ludwig and Iván Werning. 2014. "Positive Long Run Capital Taxation: Chamley-Judd Revisited." Working Paper 20441, National Bureau of Economic Research, Cambridge-MA: NBER.

\section{A Proof of Lemma 1}

Proof. We first prove that an implementable allocation satisfies the implementability constraint (15) and the aggregate resource constraint (13). Since an implementable allocation solves the individual's problem by definition, we can use the individual's optimality conditions, transversality condition for assets and the budget constraint to derive the implementability constraint. 
Furthermore, an implementable allocation satisfies the aggregate resource constraint by construction. Next, we prove that an allocation $\left\{c_{t}, l_{t}, k_{t+1}\right\}_{t=0}^{\infty}$ that satisfies (15) and (13) is implementable. We can start by defining the factor prices $r_{t}$ and $w_{t}$ such that the firm's optimality conditions hold:

$$
\begin{aligned}
r_{t} & \equiv f_{k}\left(k_{t}, l_{t}\right)-\delta, \quad t>0, \\
w_{t} & \equiv f_{l}\left(k_{t}, l_{t}\right), \quad t \geq 0 .
\end{aligned}
$$

Given the factor prices, we can use the individual's first-order conditions to define the proportional taxes $\left\{\tau_{t}^{L}, \tau_{t+1}^{K}\right\}_{t=0}^{\infty}$ that implement the allocation $\left\{c_{t}, l_{t}, k_{t+1}\right\}_{t=0}^{\infty}$ :

$$
\begin{aligned}
\tau_{t}^{L} & \equiv 1+\frac{u_{l_{t}}}{w_{t} u_{c_{t}}}, \quad t>0, \\
\tau_{t+1}^{K} r_{t+1} & \equiv 1+r_{t+1}-\frac{u_{c_{t}}}{\beta u_{c_{t+1}}}, \quad t>0 .
\end{aligned}
$$

Since we know the initial asset endowment $a_{0}=0$ and the paths of consumption and labour and the net prices of labour and future consumption, we can recursively define the private asset holdings $\left\{a_{t+1}\right\}_{t=0}^{\infty}$ such that the individiual's budget constraint (2) holds:

$$
a_{t+1} \equiv\left(1+\left(1-\tau_{t}^{K}\right) r_{t}\right)+\left(1-\tau_{t}^{L}\right) w_{t} l_{t}-c_{t}, \quad t>0,
$$

By iterating the equation above forward and using the expressions for the net prices and the implementability constraint, we can obtain the transversality condition for assets (3). In order to prove that the allocation satisfies the government budget constraint, we subtract the individual budget constraint (2) from the aggregate resource constraint (13) and use the linear homogeneity of the production function (constant returns to scale):

$$
a_{t+1}-k_{t+1}=\left(1+r_{t}\right)\left(a_{t}-k_{t}\right)+g_{t}-\tau_{t}^{K} r_{t} a_{t}-\tau_{t}^{L} w_{t} l_{t}, \quad t>0 .
$$

If we denote $d_{t} \equiv a_{t}-k_{t}$, we obtain both the condition for capital-market clearing (14) and the government budget constraint (8), thus proving that the implication holds in both directions.

\section{B Proof Lemma 2}

In this section, we assume that utility is time separable, additively separable between consumption and leisure and homothetic in consumption:

$$
U=\sum_{t=0}^{\infty} \beta^{t}\left(u\left(c_{t}\right)-v\left(l_{t}\right)\right),
$$

where $u\left(c_{t}\right)$ is homothetic. By the separability of the utility function, we can rewrite the general equilibrium elasticity $\varepsilon_{t}^{c}$ as:

$$
\varepsilon_{t}^{c}=\frac{u_{c_{t} c_{t}} c_{t}}{u_{c_{t}}}, \quad t>0 .
$$


By homotheticity of $u$, we know that the following holds for any level of $\phi$ :

$$
\frac{u_{c_{t}}\left(c_{t}\right)}{u_{c_{t+1}}\left(c_{t+1}\right)}=\frac{u_{c_{t}}\left(\phi c_{t}\right)}{u_{c_{t+1}}\left(\phi c_{t+1}\right)}, \quad t>0
$$

Since the expression above can be treated as an identity, we can also differentiate it w.r.t $\phi$ and set $\phi$ to 1 :

$$
\frac{u_{c_{t} c_{t}} c_{t}}{u_{c_{t}}}=\frac{u_{c_{t+1} c_{t+1}} c_{t+1}}{u_{c_{t+1}}}, \quad t>0
$$

Since the expression above holds for any $t$, we can conclude that $\varepsilon_{t}^{c}$ is constant for all $t$.

\section{Proof of Lemma 3}

When the agent's time horizon is finite and her preferences are not time-additive, the government's Lagrangian becomes:

$$
\begin{aligned}
\mathcal{L} & =U\left(c_{1}, \ldots, c_{T}, l_{1}, \ldots, l_{T}\right)+\theta\left(\sum_{t=0}^{T} U_{c_{t}} c_{t}+U_{l_{t}} l_{t}\right) \\
& +\sum_{t=0}^{T} \eta_{t}\left(f\left(k_{t}, l_{t}\right)-c_{t}-g_{t}-k_{t+1}+(1-\delta) k_{t}\right)
\end{aligned}
$$

where $\theta$ is the multiplier on the implementability constraint and $\eta_{t}$ is the multiplier on the period $t$ aggregate resource constraint.

We can define the general equilibrium elasticities $H_{t}^{c}$ and $H_{t}^{l}$, which are the equivalent of the general equilibrium elasticities $\varepsilon_{t}^{c}$ and $\varepsilon_{t}^{l}$ in a setting without time additivity:

$$
H_{t}^{c} \equiv-\frac{\sum_{i=0}^{T}\left(U_{c_{i} c_{t}} c_{i}+U_{l_{i} c_{t}} l_{i}\right)}{U_{c_{t}}}, \quad H_{t}^{l} \equiv-\frac{\sum_{i=0}^{T}\left(U_{c_{i} l_{t}} c_{i}+U_{l_{i} l_{t}} l_{i}\right)}{U_{l_{t}}}, \quad t>0 .
$$

This allows us to rewrite the government's first-order conditions with respect to consumption $c_{t}$, labour $l_{t}$ and capital $k_{t+1}$ as, respectively:

$$
\begin{aligned}
(1+\theta) U_{c_{t}}-\theta U_{c_{t}} H_{t}^{c} & =\eta_{t}, \quad t>0, \\
(1+\theta) U_{l_{t}}-\theta U_{l_{t}} H_{t}^{l} & =-\eta_{t} f_{l_{t}}, \quad t>0, \\
\frac{\eta_{t}}{\eta_{t+1}}=1+f_{k_{t+1}}-\delta & =1+r_{t+1}, \quad t>0 .
\end{aligned}
$$

Using the weak separability of $U$, we can rewrite the marginal rate of substitution between present and future consumption as:

$$
\frac{U_{c_{t}}}{U_{c_{t+1}}}=\frac{h_{c_{t}}}{h_{c_{t+1}}}, \quad t>0
$$


Since $h$ is homothetic, the ratio $\frac{h_{c_{t}}}{h_{c_{t+1}}}$ is a function $\Omega$ of $c_{t}$ and $c_{t+1}$ only:

$$
\frac{h_{c_{t}}}{h_{c_{t+1}}}=\Omega\left(\frac{c_{t}}{c_{t+1}}\right), \quad t>0
$$

This allows us to rewrite the Euler equation (7) as:

$$
\frac{c_{t}}{c_{t+1}}=\Omega^{-1}\left(R_{t+1}\right), \quad R_{t+1} \equiv 1+\left(1-\tau_{t+1}^{K}\right) r_{t+1}, \quad t>0 .
$$

This expression shows that the consumption goods are linearly related in every period:

$$
c_{t+1}=\gamma_{t+1}^{C} c_{t}, \quad t>0
$$

where $\gamma_{t+1}^{C}$ is a constant. This suggests that at the optimum, the entire vector of consumptions $\left(c_{0}, \ldots, c_{t}, \ldots, c_{T}\right)$ can be expressed as:

$$
\left(c_{0}, \ldots, c_{s}, \ldots, c_{T}\right)=\left(\gamma_{0}^{C}, \ldots, \gamma_{s}^{C}, \ldots, \gamma_{T}^{C}\right) c_{t}, \quad t>0
$$

where $\gamma_{s}^{C}=1$ if $s=t$ for all $t$. Similarly, the entire vector of labour supplies can be expressed as:

$$
\left(l_{0}, \ldots, l_{s}, \ldots, l_{T}\right)=\left(\gamma_{0}^{L}, \ldots, \gamma_{s}^{L}, \ldots, \gamma_{T}^{L}\right) l_{t}, \quad t>0,
$$

where $\gamma_{s}^{L}=1$ if $s=t$. Using the expressions above to rewrite $U$, we can express the general equilibrium elasticities in a much simpler format, while taking into account that $\gamma_{s}^{L}=\gamma_{s}^{C}=1$ if $t=s$ :

$$
\begin{aligned}
H_{t}^{c} & =-\frac{1}{U_{c_{t}}} \sum_{s=0}^{T}\left[\frac{1}{\gamma_{s}^{C} \gamma_{t}^{C}} c_{s} U_{c_{t} c_{t}}+\frac{1}{\gamma_{s}^{L} \gamma_{t}^{C}} l_{s} U_{c_{t} l_{t}}\right]=-\frac{1}{U_{c_{t}}} \sum_{s=0}^{T}\left[U_{c_{t} c_{t}} c_{t}+U_{c_{t} l_{t}} l_{t}\right], \quad t>0, \\
H_{t+1}^{c} & =-\frac{\gamma_{t+1}^{C}}{U_{c_{t}}} \sum_{s=0}^{T}\left[c_{t+1} \frac{1}{\left(\gamma_{t+1}^{C}\right)^{2}} U_{c_{t} c_{t}}+\frac{1}{\gamma_{t+1}^{C} \gamma_{t+1}^{L}} U_{c_{t} l_{t}} l_{t+1}\right]=-\frac{1}{U_{c_{t}}} \sum_{s=0}^{T}\left[U_{c_{t} c_{t}} c_{t}+U_{c_{t} l_{t}} l_{t}\right] .
\end{aligned}
$$

Equations (78) and (79) show that due to the properties of the utility function, the general equilibrium elasticity for consumption is constant, which suggests that $H_{t}^{c}=H_{t+1}^{c}$, for all $t$. Combining this result with the government's Euler equation (19) and the individual's Euler equation (7) gives the result $\tau_{t}^{K}=0$ for all $t$.

\section{Proof of Lemma 4}

Proof. We first prove that an implementable allocation satisfies the implementability constraint (15) and the aggregate resource constraint (53). Since an implementable allocation solves the individual's problem by definition, we can use the individual's optimality conditions, transversality condition for assets and the budget constraint to derive the implementability constraint. Furthermore, an implementable allocation satisfies the aggregate resource constraint by construction. Next, we prove that an allocation $\left\{c_{t}, g_{t}, x_{t+1}\right\}_{t=0}^{\infty}$ that satisfies (15) and (53) is implementable, given the factor prices $r$ and $w$. The proof follows exactly the same steps as 
the one for the general equilibrium case in Appendix A: we use the individual's first-order conditions to calculate the taxes $\left\{\tau_{t}^{L}, \tau_{t+1}^{K}\right\}_{t=0}^{\infty}$ that would implement the allocation. We then define the private asset path such that the individual budget constraint (2) holds and use the implementability constraint (15) and the private optimality conditions (6) and (7) to prove that the transversality condition for private assets (3) holds. The last step of the proof involves subtracting the aggregate resource constraint (53) from the individual's budget constraint (2) and defining the government debt $d_{t}=a_{t}-x_{t}$. This proves that both the condition for capitalmarket equilibrium (55) and the government budget constraint (8) hold. 